\title{
Improving the Efficiency and Effectiveness of Parent Education in the Neonatal Intensive Care Unit
}

\author{
Melissa B. Gehl, MSW; Caroline C. Alter, MS; Nikki Rider, ScD, MPP; Lori G. Gunther, MS; \\ Rebecca B. Russell, MSPH
}

\begin{abstract}
Background: March of Dimes partners with hospitals across the country to implement NICU Family Support (NFS) Core Curriculum, a program providing education to parents in neonatal intensive care units (NICUs) across the country. Purpose: This NFS project's goal was to increase the efficiency and effectiveness of NICU parent education by establishing consistency, improving quality, and identifying best practices.

Methods/Search Strategy: A 5 topic curriculum was developed and implemented across NFS program sites. The project studied 4 main outcomes of interest related to efficiency and effectiveness: increase in parenting confidence, parent learning, knowledge change, and satisfaction. Data were collected from speakers and attendees immediately following educational sessions. Analytical approaches included descriptive statistics such as frequency, percentage, and response rate, and inferential approaches such as $t$ test, $\chi^{2}$, and analysis of variance.

Findings/Results: Findings suggest that the NFS Core Curriculum improved both program efficiency and effectiveness. Sessions fully implemented according to recommended strategies had better outcomes than sessions not fully implemented according to recommended strategies $(P<.0001)$. Across the 3648 attendees at 41 sites, $77 \%$ of parents reported learning "a lot" at the session they attended and $85 \%$ of attendees reported increased confidence. Attendees also reported positive knowledge change and high satisfaction.

Implications for Practice: Parent education best practices identified through this initiative can be utilized for future NFS Core Curriculum topics and potentially generalized to all NICU parent education and family education in other hospital intensive care units.

Implications for Research: Content and best practices identified through this project will require regular review to ensure medical accuracy and appropriateness of best practices as the physical design of NICUs evolves.

Key Words: neonatal intensive care, NICU, parent confidence, parent education, parent learning, parent satisfaction
\end{abstract}

nfants in the neonatal intensive care unit (NICU) may have been born prematurely, have a medical condition that requires intensive care, or experienced a traumatic birth. Many families come into the NICU unprepared to care for an infant with unique medical needs and must learn to do so before taking their infant home. ${ }^{1}$ Medical experts and NICU parents agree that educating families is a key component to a parent's involvement in his or her infant's care while in the NICU and his or her subsequent ability to care for his or her infant postdischarge. ${ }^{1-3}$ Nurses and other care providers in the NICU have the

Author Affiliation: March of Dimes, Mission Department, Arlington, Virginia (Mss Gehl, Alter, Russell, and Gunther). Dr Rider is an independent consultant, Daphne, AL.

The authors declare no conflicts of interest.

This is an open-access article distributed under the terms of the Creative Commons Attribution-Non Commercial-No Derivatives License 4.0 (CCBY-NC-ND), where it is permissible to download and share the work provided it is properly cited. The work cannot be changed in any way or used commercially without permission from the journal.

Correspondence: Lori G. Gunther, MS, March of Dimes, 1550 Crystal Dr, Ste 1300, Arlington, VA 22202 (loriggunther@gmail.com).

Copyright (C) 2019 The Authors. Published by Wolters Kluwer Health, Inc. on behalf of the National Association of Neonatal Nurses

DOI: 10.1097/ANC.0000000000000644 immense task of equipping parents with this knowledge in a relatively short period of time. ${ }^{4}$

\section{BACKGROUND AND SIGNIFICANCE}

A variety of parent education formats have been reported as being effective in improving parental/caregiver confidence and knowledge. These formats include group education sessions,${ }^{5-8}$ audiotapes,${ }^{9}$ videos, ${ }^{10}$ and bedside simulations. ${ }^{2,11,12}$ The literature also reports that educators often vary in their staff role in the NICU, including nurses, ${ }^{8,13}$ doctors, ${ }^{14}$ therapists, ${ }^{15}$ and parent-to-parent managers. ${ }^{16}$ Content areas addressed in NICU education programs also vary widely. Brett et $\mathrm{al}^{17}$ categorize topics as "individualized developmental and behavioral care; behavioral assessment scales; breastfeeding, kangaroo-care and infant-massage programs; support forums for parents; the alleviation of parental stress; preparing parents for seeing their infant for the first time; communication and information sharing; and discharge planning."

Efficiently and effectively educating families in the NICU setting can be particularly challenging. With an average length of stay in a level III or IV NICU of 14 days, ${ }^{4}$ parents may not have time for 
comprehensive education. One study showed that $43 \%$ of NICU parents may have a low level of health literacy, which impacts their ability to understand, retain, and process health information..$^{18}$ In addition, many parents report high levels of stress while their infant is in the NICU, ${ }^{19}$ which can also significantly impact their ability to retain what has been learned. ${ }^{20}$

Standardized parent education programs have shown benefits to parents and infants while also creating efficiencies. A randomized controlled trial of a standardized parent education intervention that utilized audiotapes showed a reduced length of NICU stay. ${ }^{9}$ Through this intervention, parents were found to have improved mental health outcomes and displayed more positive interactions with their infant. Given the myriad of options in the delivery of NICU parent education in conjunction with the challenging learning environment, evidence is needed on factors that lead to the best outcomes in terms of parent learning, confidence, and satisfaction.

March of Dimes partners with hospitals across the country to implement NICU Family Support (NFS), a program dedicated to educating NICU families, educating NICU staff, and improving the overall NICU experience. Each NICU has a Family Support Program Coordinator (NFS Program Coordinator) responsible for implementing its NFS program with the direction and support of national March of Dimes NICU Family Support Program Directors (NFS Program Directors).

Historically, NFS Program Coordinators were instructed to hold educational programs tailored to the unique needs of the families in their NICU. An informal survey of 31 NFS sites in October 2012 revealed that nearly 50 different parent education topics were being delivered through the NFS program with varied content and speakers. This resulted in several challenges:

1. NFS Program Directors and NFS Program Coordinators did not know whether the education provided to families was effective.

2. While satisfaction surveys were utilized, analysis was done individually by sites and was not aggregated nationally.

3. NFS Program Coordinators were unsure of which content to cover and the best way to implement parent education on those topics.

4. NFS Program Directors had no means to ensure that quality education was provided consistently across instructors, sites, and settings.

NFS Program Directors hypothesized that if more guidance was provided on how to implement in-person parent education, the education would be of higher quality and more learning would occur. As a first step toward efficiency and standardization, the NFS program provided 1 parent education class on kangaroo care, called Close to $\mathrm{Me}$, which included a presentation

\section{What This Study Adds}

- An in-depth look at the implementation of a largescale, multisite quality improvement project.

- The impact of a standardized education program in the neonatal intensive care unit on parental learning, confidence, and satisfaction.

- Best practices for educating parents in the neonatal intensive care unit.

and speaking points. A 2014 study involving the Close to Me parent education curriculum showed that the program was also effective and parents who attended a Close to Me session had greater rates of learning on the topic of kangaroo care than the control group that did not receive the education. ${ }^{6}$

\section{PROGRAM DESCRIPTION}

The March of Dimes NICU Family Support Core Curriculum (Core Curriculum) was created to establish consistency in the delivery of information and to provide support to NFS program sites. The evaluation was designed to examine the efficiency and effectiveness of education on families and best practices in NICU parent education. Curricula were developed for 5 topic areas that were applicable to nearly all NICU families:

- Caring for Your Baby in the NICU

- Close to Me

- Caring for Your Baby at Home (Discharge Preparation)

- Infant Nutrition

- Caring for Your Family Means Caring for Yourself

To create efficiencies, the curriculum for each topic area included standards (recommended

TABLE 1. Description of NICU Family
Support Core Curriculum
NICU Family Support Core Curriculum
Guidance
Recommended speakers
Learning objectives
Key messages
Recommended materials
Recommended activities
Recommended discussion
Evaluation tools
Session report
Speaker assessment
Attendee assessment
Abbreviation: NICU, neonatal intensive care unit.


speakers, learning objectives, key messages, and recommended activities, materials, and conversation ideas), tools to support the speaker (guidelines sheets, speaking points, and bibliographies), and tailored evaluation tools, as shown in Table 1.

To implement the Core Curriculum, NFS partner hospitals were given all necessary guidelines, tools, and materials as part of their partnership benefit. The NFS Program Coordinators were instructed to offer at least 2 classes per month, in either a group format (group) or with an individual family at their infant's bedside (bedside). Classes were to be held according to Core Curriculum-recommended implementation strategies (fully implemented as recommended) with an emphasis on utilizing a recommended speaker, covering all learning objectives and key messages and, in ideal circumstances, incorporating at least 1 recommended activity or 1 recommended material.

\section{STUDY OF INTERVENTION}

A formative evaluation design was chosen to assess the content of the curriculum and its implementation. The focus was to identify best practices to understand efficiency gains and guide future program quality and effectiveness. Therefore, the evaluation was designed to provide ongoing recommendations to improve parental/caregiver confidence, learning, self-reported knowledge change, and satisfaction. To promote efficiency and standardization, training of NFS Program Coordinators was coled by the NFS Program Directors and evaluation staff and all instructional materials were written to include delivery of the curriculum with evaluation as an integrated component. After a short pilot phase, the NFS Core Curriculum launched nationally in July 2014.

\section{METHODS}

The NFS Program Coordinators were responsible for collecting data about the efficiency and effectiveness of each session. Their training included how to assign and track unique session and speaker identifiers to preserve privacy of individuals and also to allow for the linkage of the 3 data collection tools developed for each of the 5 topics:

1. Session report form (session): Completed by the NFS Program Coordinator each time a session was offered. Items were filled out before, during, and at the close of the session. This form contained administrative information about the session, such as the date, attendance, format (group or bedside), speaker information, and observable information regarding the material covered during the session.

2. Speaker assessment form (speaker): Completed by the primary speaker following the first time he or she led a session on each topic at the site.
This form contained questions on the speaker's experience leading the session and suggestions for improvement of the class.

3. Attendee assessment form (attendee): Each attendee had an opportunity to complete an assessment form immediately following the end of every session. This form contained questions on parenting confidence, perception of knowledge change, satisfaction with the session, and a true/false quiz regarding session content. To assess whether the session impacted knowledge change, attendees were asked to report on what they knew before the session and what they knew following the session.

The 3 data sources captured a multidimensional picture of the process and outcomes of each session. The paper-and-pencil forms used Likert-type scales, multiple choice questions, check all that apply items, and had space for comments. The consistent format of the forms allowed for aggregation across topics and sites, while also mapping directly to the individual topic guidelines.

The evaluation covered a $21 / 2$-year period from July 2014 through December 2016. Data were collected via the session and speaker forms throughout the entire evaluation period. Attendee forms were collected only between July 2014 and December 2015. Data from paper forms were entered into Qualtrics, an online survey platform, and then 15 separate data files, 1 for each topic (5) and each form type (3), were downloaded from Qualtrics and imported into IBM SPSS Statistics version 19 (SPSS). The SPSS was used to clean the data and create working data files by linking the data from the 3 forms using a unique session identifier to provide more complete information on the efficiency and effectiveness of each individual session. Findings that reference the linked files refer to data files that linked the session, speaker, and attendee forms. Findings that reference unlinked files refer to data collected via the session form only.

\section{MEASURES}

With a focus on identifying best practices to guide future program quality, the project was designed to evaluate the efficiency and effectiveness of the curriculum. Efficiency was assessed through the examination of adherence to curriculum recommendations including use of qualified and prepared speakers and incorporation of recommended messages and materials. The evaluation included 3 main outcomes of interest related to effectiveness: increase in parenting confidence; parent learning and knowledge change; and satisfaction. Parenting confidence and parent learning/knowledge change were chosen because of their anticipated positive impact on families' ability to care for their high-risk infant during and after the 
hospitalization..$^{1,3}$ Satisfaction was chosen because of its association with the increasing priority of positive patient experience among hospital leaders. ${ }^{21-24}$

Parenting confidence was measured as the percentage of attendees who reported increased confidence after attending the session. Parenting confidence was measured on a 3-point Likert scale with the following response options: decreased, stayed the same, and increased. The data were coded as a dichotomous variable: increased or did not increase (decreased or stayed the same) and percentages for each of the 2 response options were calculated.

The mean satisfaction scale represents an average across the 3 satisfaction statements on the attendee assessment form ("For this parent hour, how satisfied or dissatisfied are you with the..."). Each of the 3 statements received a score that ranged from very dissatisfied (1) to very satisfied (4) and an average across the 3 statements was calculated.

Parent learning and knowledge change were examined using 2 approaches: (1) overall selfreported learning and (2) a postsession learning score. Self-report learning was assessed by asking attendees to respond to the statement "How much did you learn overall during this parent hour?" Response options included as follows: nothing, a little bit, a lot, and does not apply. Findings from overall self-reported learning are based on the percentages of parental responses to those options. The postsession learning score was based on four 2-part questions. Each statement asked attendees to report their agreement with 4 topic-specific statements about what they knew before the session and what they knew after attending the session. The 4-point Likert responses ranged from strongly disagree (1) to strongly agree (4). If an attendee answered all 4 statements, an average score was created for both the before responses and the after responses. If a respondent had both a before and an after score, the postsession learning score was created by subtracting the average after score from the average before score. A small portion of postsession learning scores were negative, which indicated that a parent reported knowing more before the session than after the session $(n=60)$. A score of zero indicated no reported knowledge change $(\mathrm{n}=529)$, while the remainder of the scores were positive, indicating that a parent reported learning from the session.

Ongoing data quality and monitoring ensured that all sites were compliant with program implementation and data reporting. Project data were examined on a quarterly basis by evaluation staff and shared with NFS Program Coordinators who compared the study data with program administrative data to help identify reporting issues such as errors in ID assignment that would prevent the 3 data sources from being linked to one another.

\section{ANALYSIS}

All data were analyzed using SAS 9.3 (SAS Institute Inc, Cary, North Carolina). Two data files were used for analysis: (1) the unlinked session data file that included data collected between July 2014 and December 2016 and (2) the linked session-attendeespeaker file, which was limited to data collected from the session, speaker, and attendee forms between July 2014 and December 2015 and included only observations from attendees whose attendee's assessment form could be linked to the session report form and the speaker assessment form. Analysis was limited to the sites that consistently participated in the full Core Curriculum program. Data were excluded from sites that did not offer at least 1 session every 6 months between July 2014 and December 2016. Analytical approaches included descriptive statistics (frequency, percentage, and response rate) and inferential approaches ( $t$ test, $\chi^{2}$, and analysis of variance), with significance set at $P<.05$.

To assess whether there were influential sites or speakers, a sensitivity analysis was undertaken. All key outcomes presented in this article were measured with and without data from select sites and speakers. Findings were then compared to ensure that outcomes were not influenced by a single site or a particular session speaker. Data were also analyzed to assess nonresponse bias by comparing findings from linked data files with findings from unlinked data files. To assess whether selection bias was present, findings from the data set that included only those sites that offered sessions consistently were also compared with the full data set that included all sites. For the sensitivity analyses described previously, differences in findings between the full and reduced data sets were not significant.

\section{ETHICAL CONSIDERATIONS}

This project was designed for internal quality improvement and institutional review board approval was not sought. However, steps were taken to ensure that attendees were treated ethically and data were secure. Session attendees were assured that completion of the evaluation was voluntary and that their evaluation forms were anonymous. No attendee identifiers were collected or reported, and the NFS Program Coordinators were trained on ways to maintain anonymity of responses during collection of attendee forms. Data were transmitted to the March of Dimes National Office through Qualtrics. Hard copies of all forms were retained in a locked, on-site location for 1 year. Form data were accessible only by evaluation staff at the March of Dimes National Office through a passwordprotected site. 


\section{RESULTS}

The session data file included data collected via the session report form between July 2014 and December 2016 ( $n=3399$ sessions). Sessions offered but not attended by any attendees are not included in the results $(\mathrm{n}=720)$. Between July 2014 and December 2016, 13,350 individuals attended 1 of 3399 sessions held across 41 unique sites. Of those held sessions, a total of $806(24 \%)$ were held at the patient's bedside. Three percent of sessions $(n=106)$ were held in Spanish. The average session was 53 minutes (standard deviation $=21$ minutes) and had 3.93 attendees (standard deviation $=3.24$ ). Group sessions had an average of 4.6 attendees compared with an average of 1.8 attendees at bedside sessions. Table 2 displays the number and percentage of sessions with characteristics of interest overall and by time period.

\section{Efficiency}

Speaker preparation and the use of recommended messages and materials were examined overall and by year and format to understand how closely sessions adhered to recommended implementation strategies. Table 3 shows the number and percentage of sessions offered according to recommended implementation strategies by year and format.

Over the study period, $80 \%$ of sessions were offered by a speaker who was qualified and prepared-defined as a speaker with an appropriate educational background who received the topic-specific guidelines and supplement before teaching his or her first session. Nearly $60 \%$ of sessions $(58 \%$, $\mathrm{n}=1961)$ covered all key messages and learning objectives and used at least 1 recommended material or conducted at least 1 recommended activity (recommended messages and materials). Just over a third of sessions $(36 \%, \mathrm{n}=1212)$ were fully implemented as recommended with a qualified and prepared speaker and use of recommended messages and materials.

Across time, sessions held in 2014 and 2015 were more likely to have speakers who reported the use of recommended messages and materials in their sessions $(P<.0001)$. Sessions in 2014 and 2015 were also more likely to be fully implemented as recommended $(P<.0001)$ compared with sessions in 2016. While there were no differences observed across time, speakers in the group setting were more likely to be classified as qualified and prepared than speakers at the bedside setting (83\% compared with $72 \%, P<.0001)$. Group session speakers were also more likely to use recommended messages and materials in their sessions $(P<.0001)$. Sessions held at bedside were less likely to be fully implemented as recommended $(P<.0001)$.

\section{Effectiveness}

Table 4 displays self-reported parental learning, knowledge change, confidence, and mean satisfaction. Across the 3648 attendees at 41 sites, $77 \%$ $(\mathrm{n}=2795)$ of parents reported learning "a lot" at the session they attended. Knowledge change, measured as the difference in mean before and after scores, indicates that most attendees reported knowing more at the end of a session than they did before attending. Overall, $85 \%$ of attendees reported increased confidence following the sessions $(\mathrm{n}=$ 3052). Attendees also reported high satisfaction with sessions (mean is 3.78 out of 4 ).

Parents who attended sessions in 2015 reported learning "a lot" more frequently than their counterparts attending sessions in 2014 ( $P$ value is .0237).

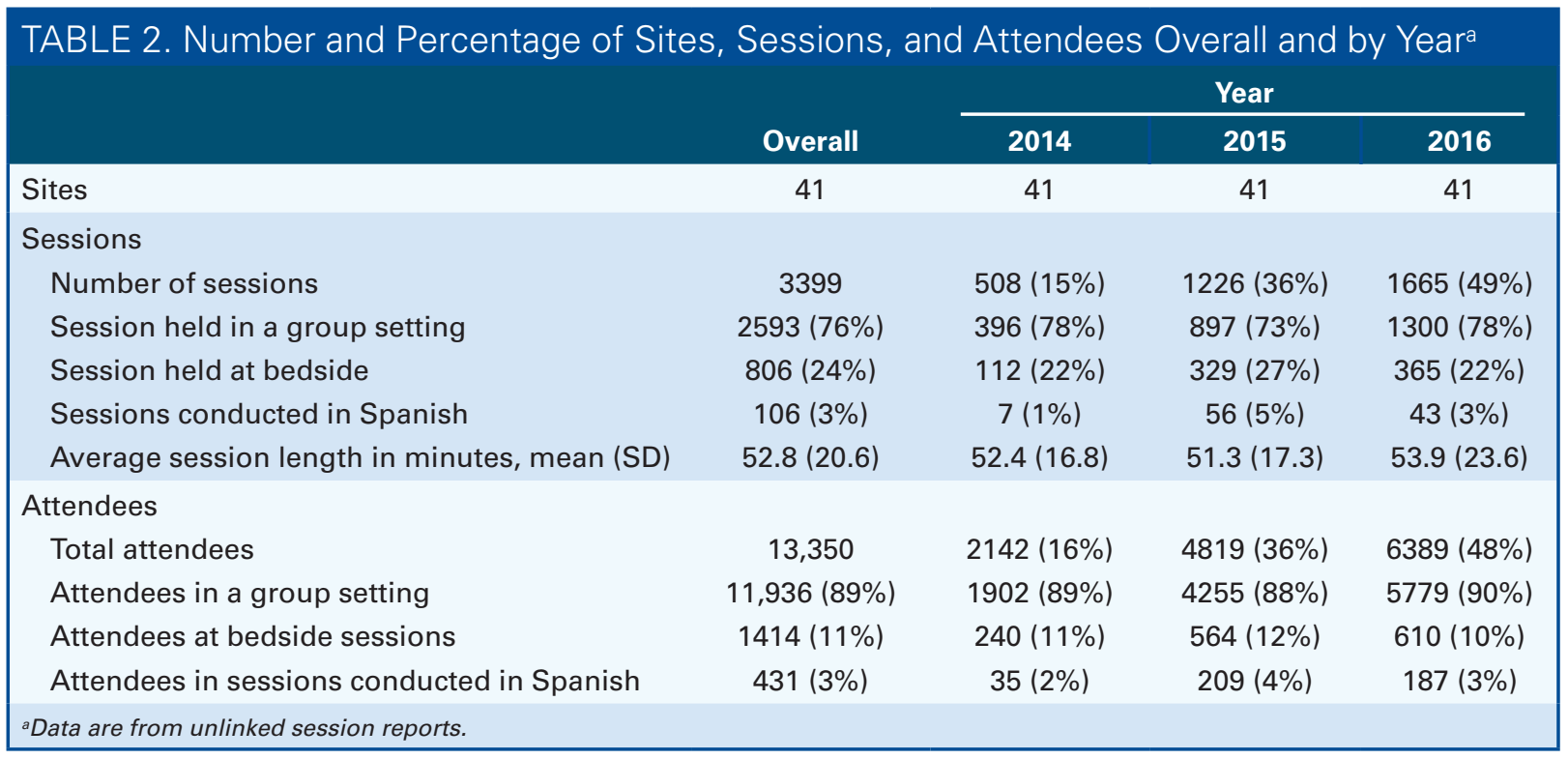




\begin{tabular}{|c|c|c|c|c|c|c|}
\hline & \multirow[b]{2}{*}{ Overall } & \multicolumn{3}{|c|}{ Years } & \multicolumn{2}{|c|}{ Format } \\
\hline & & 2014 & 2015 & 2016 & Group & Bedside \\
\hline Number of sites & 41 & $41(100 \%)$ & $41(100 \%)$ & $41(100 \%)$ & $41(100 \%)$ & $27(66 \%)$ \\
\hline Total sessions & 3399 & $508(15 \%)$ & $1225(36 \%)$ & $1665(49 \%)$ & $2593(76 \%)$ & $806(24 \%)$ \\
\hline Speaker qualified and prepared & $2729(80 \%)$ & $418(82 \%)$ & $990(81 \%)$ & $1321(79 \%)$ & $2146(83 \%)$ & $580(72 \%)^{b}$ \\
\hline $\begin{array}{l}\text { Recommended messages and } \\
\text { materials provided }\end{array}$ & $1961(58 \%)$ & $336(66 \%)$ & $780(63 \%)$ & $845(51 \%)^{b}$ & $1418(55 \%)$ & $543(67 \%)^{b}$ \\
\hline $\begin{array}{l}\text { Sessions fully implemented as } \\
\text { recommended }\end{array}$ & $1212(36 \%)$ & $217(43 \%)$ & $469(38 \%)$ & $526(32 \%)^{b}$ & $990(38 \%)$ & $222(28 \%)^{b}$ \\
\hline $\begin{array}{l}{ }^{a} \text { Data are from the unlinked session file } \\
{ }^{b} \text { Significant at } P<.0001 \text {. }\end{array}$ & & & & & & \\
\hline
\end{tabular}

There were no significant differences in parent knowledge change, confidence, or mean satisfaction over time. Parents who attended bedside sessions reported learning "a lot" more frequently than their counterparts attending group sessions $(P<.0001)$. Furthermore, attendees at bedside sessions reported learning more and higher confidence and satisfaction than parents at group sessions.

TABLE 4. Number and Percentage of Attendees Reporting Learning, Knowledge Change, Increased Confidence, and Mean Satisfaction ${ }^{a}$

\begin{tabular}{|c|c|c|c|c|c|}
\hline & \multirow[b]{2}{*}{ Overall } & \multicolumn{2}{|c|}{ Years } & \multicolumn{2}{|c|}{ Format } \\
\hline & & 2014 & 2015 & Group & Bedside \\
\hline Number of sites & 41 & 41 & 36 & 39 & 17 \\
\hline Number of attendees & 3648 & $1310(36 \%)$ & $3648(64 \%)$ & $3307(91 \%)$ & $341(9 \%)$ \\
\hline \multicolumn{6}{|l|}{ Parental learning } \\
\hline Nothing & $11(0.3 \%)$ & $7(0.5 \%)$ & $4(0.2 \%)$ & $11(0.3 \%)$ & $0(0 \%)$ \\
\hline A little bit & $605(17 \%)$ & $241(19 \%)$ & $364(16 \%)$ & $584(18 \%)$ & $21(6 \%)$ \\
\hline A lot & 2795 (77\%) & $978(76 \%)$ & $1817(78 \%)^{\mathrm{b}}$ & $2483(76 \%)$ & $312(92 \%)^{b}$ \\
\hline Does not apply & 197 (5\%) & $65(5 \%)$ & $132(6 \%)$ & $190(6 \%)$ & $7(2 \%)$ \\
\hline $\mathrm{n}$ & 3608 & 1291 & 2317 & 3268 & 340 \\
\hline Missing & 40 & 40 & 40 & 40 & 40 \\
\hline \multicolumn{6}{|l|}{ Knowledge change } \\
\hline Mean before score & 2.92 & 2.92 & 2.92 & 3.00 & 2.18 \\
\hline Mean after score & 3.80 & 3.76 & 3.81 & 3.78 & 3.88 \\
\hline Mean change & 0.87 & 0.84 & $0.89^{b}$ & 0.78 & $1.70^{\mathrm{b}}$ \\
\hline $\mathrm{n}$ & 3230 & 1160 & 2070 & 2908 & 322 \\
\hline \multicolumn{6}{|c|}{$\begin{array}{l}\text { Confidence in parenting or } \\
\text { caregiving }\end{array}$} \\
\hline Decreased & $5(0.1 \%)$ & $2(0.2 \%)$ & $3(0.1 \%)$ & $5(0.2 \%)$ & $0(0 \%)$ \\
\hline Stayed the same & $540(15 \%)$ & $212(16 \%)$ & $328(14 \%)$ & $516(16 \%)$ & $24(7 \%)$ \\
\hline Increased & $3052(85 \%)$ & $1078(83 \%)$ & $1974(86 \%)$ & 2739 (84\%) & $313(93 \%)^{b}$ \\
\hline $\mathrm{n}$ & 3597 & 1292 & 2305 & 3260 & 337 \\
\hline Missing & 51 & 51 & 51 & 51 & 51 \\
\hline \multicolumn{6}{|c|}{ Mean parental satisfaction } \\
\hline Mean & 3.78 & 3.75 & 3.78 & 3.76 & $3.86^{\mathrm{b}}$ \\
\hline $\mathrm{n}$ & 3607 & 1289 & 2318 & 3266 & 341 \\
\hline Missing & 41 & 41 & 41 & 41 & 41 \\
\hline
\end{tabular}




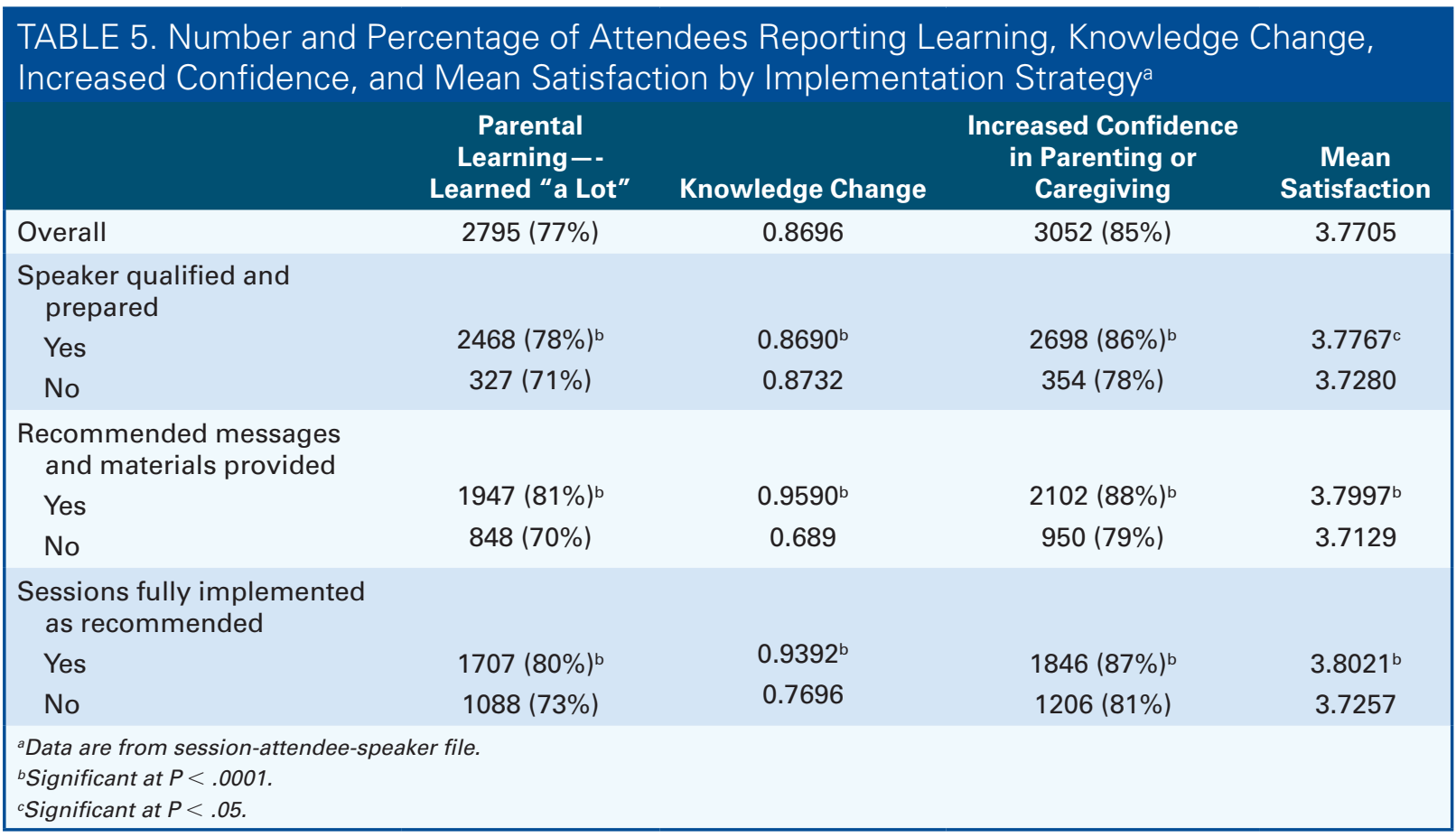

\section{Combined Efficiency and Effectiveness}

As shown in Table 5, efficiency and effectiveness outcomes of interest were also examined by implementation strategy to identify potential best practices. Findings show that there was a statistically significant difference in parental learning, knowledge change, confidence, and mean satisfaction in sessions fully implemented as recommended compared with sessions that did not adhere to those implementation strategies. Overall, attendees reported learning "a lot" more frequently, increased confidence, and higher mean satisfaction when the speaker was qualified and prepared. Sessions where recommended messages and materials were used and sessions that were fully implemented as recommended had better outcomes in terms of parental learning, knowledge change, confidence, and mean satisfaction than sessions that did not adhere to those implementation strategies.

\section{DISCUSSION}

The NFS program sites that were included in this quality improvement project included university medical centers, regional perinatal centers, and children's hospitals serving both surgical and primarily premature infant populations. This diverse sample of hospital settings makes it likely that findings are applicable beyond program sites.

\section{Efficiency}

The curriculum allowed for the creation of efficiencies and the identification of best practices in the delivery of NICU parent education during a high stress and often short period of time. These best practices include educating parents at the bedside, utilizing a wellprepared speaker, and providing consistent messaging and materials in a similar manner across all content areas. Each of these strategies was associated with higher rates of learning, knowledge change, and increased parenting confidence and satisfaction. For bedside settings, having a well-prepared speaker may be less important than in a group setting.

This quality improvement initiative had a positive impact not only on those who were educated but also on NFS Program Coordinators and NICU staff who did not have to spend time creating and refining parent education classes. Initially, there was resistance to incorporating standardized curricula into existing parent education among NFS Program Coordinators. The NFS Program Directors prioritized Core Curriculum implementation support and resistance decreased significantly after the program was implemented.

Over time, the data showed that Core Curriculum sessions were less likely to be fully implemented as recommended. However, findings show that even with the relaxed practices in delivering the curriculum, there were still positive effects on programmatic outcomes. It is possible that over time as NFS Program Coordinators and speakers became more familiar with the curriculum, they were less reliant on referring to the recommended messages and materials for each session.

Through evaluation and feedback, NFS Program Directors identified that the curriculum for Caring for Your Family Means Caring for Yourself was seldom offered or attended. A review of comments from attendee assessment forms revealed that key messages for these sessions were focused on too 
narrow an audience. In addition, it was found that NFS Program Coordinators were not offering the class based on family feedback they received. At the end of the evaluation period, the content of this class was adapted to address the needs of more parents. The topic was then held more often and was better received by NICU families. Furthermore, due to the high rates of learning, confidence, and satisfaction seen in the evaluation phase of this project, 2 additional topics were added to address the important issues of infection control and developmental care, with more topics to be added in the future. To expand access to the Core Curriculum beyond NFS program sites, videos of 3 topics were made available on the free March of Dimes app, My NICU Baby. In 2018, this app was accessed by more than 10,000 users.

\section{Effectiveness}

This quality improvement initiative demonstrated that the Core Curriculum is a highly effective educational program that resulted in parental learning, high attendee satisfaction with the session, and increased parenting confidence. The success of bedside education in increasing learning, confidence, and satisfaction, even when sessions were not fully implemented as recommended, was an unexpected finding. It was initially thought that a group learning environment would foster conversation leading to better learning and a sense of community that would positively impact parental learning, confidence, and satisfaction. However, findings suggest that the sessions held at bedside allowed for a more favorable learning environment. After sharing the preliminary results on the effectiveness of bedside education with NFS Program Coordinators, many sites increased the bedside offerings. This has allowed the program to effectively meet and educate parents where they are and has addressed inefficiencies in scheduling sessions that result in no attendees.

\section{Limitations}

Nonresponse could not be fully examined and nonresponse bias could impact findings. The $70 \%$ attendee response rate is remarkable, given attendees completed the assessment while they had infants in the NICU; however, it is possible that factors associated with the $30 \%$ of attendees who did not respond are nonrandom. Data were self-reported and subject to respondent bias. Given that parents and caregivers participated in the program while having an infant in the NICU, pre- and postsession testing was not a reasonable expectation. The results on parental learning and knowledge change were based on attendee perception. Since attendees completed their assessment form immediately following the session, self-reported changes in learning, knowledge, and confidence were more likely to result from session content rather than practice with their infant in the NICU. However, it is possible that session attendees reported increases in learning, knowledge, and confidence because those were anticipated program outcomes.

\section{CONCLUSIONS}

Through the creation of a standardized parent education curriculum, NFS Program Directors were able to identify practices that led to effectively educating NICU families. While this clearly has a positive impact on families, it also supports the needs of NICU staff who benefit from increased efficiency and hospital leaders who prioritize satisfaction as part of the patient experience. ${ }^{24}$

Parent education best practices identified through this initiative can be utilized for future Core Curriculum topics and for efficiently and effectively educating families in other hospital intensive care units. Content and best practices identified through this project will require regular review. Specifically, key messages and learning objectives provided through the Core Curriculum will necessitate regular review for medical accuracy. In addition, as the physical design of NICUs evolves, best practices for educating families may evolve as well.

More study is required to understand the link between best practices and the delivery of education to improved outcomes for infants in the NICU and at home. Furthermore, if future evaluation studies

\section{Summary of Recommendations for Clinical Practice and Research}

\begin{tabular}{|ll} 
What we know: & - Effectively educating parents of NICU infants is critically important. \\
& - Educating families in the NICU setting can be particularly challenging. \\
& - A variety of parent education formats have been reported as having \\
positive outcomes on a parent's ability to care for his or her infant.
\end{tabular}


collected and tracked infant health data, March of Dimes could begin to understand program effectiveness and whether the Core Curriculum program influences infant health outcomes as well as their life trajectory. Understanding best practices in NICU parent education ensures that NICU staff can maximize learning opportunities while also increasing parental and caregiver confidence, knowledge, and satisfaction.

\section{Acknowledgments}

We thank Jane Manweiler for her contributions to the evaluation design, data collection, and preliminary data analyses. We also thank the March of Dimes NICU Family Support Program Coordinators who implemented the program at their sites with rigor and efficiency.

\section{References}

1. Bell EF. American Academy of Pediatrics: committee on fetus and newborn. Hospital discharge of the high-risk infant. Pediatrics. 2008; 122(5):1119-1126.

2. Cleveland LM. Parenting in the neonatal intensive care unit. J Obstet Gynecol Neonatal Nurs. 2008;37(6):666-691.

3. Burnham N, Feeley N, Sherrard K. Parents' perceptions regarding readiness for their infant's discharge from the NICU. Neonatal Netw. 2013;32(5):324-334

4. March of Dimes Perinatal Data Center. National Perinatal Information System/Quality Analytic Services. Special Care Nursery Admissions. White Plains, NY: March of Dimes Perinatal Data Center; 2011.

5. Bracht $\mathrm{M}, \mathrm{O}^{\prime}$ Leary $\mathrm{L}$, Lee SK, O'Brien K. Implementing familyintegrated care in the NICU: a parent education and support program. Adv Neonatal Care. 2013;13(2):115-126.

6. Cooper L, Morrill A, Russell RB, Gooding JS, Miller L, Berns SD. Close to Me: enhancing kangaroo care practice for NICU staff and parents. Adv Neonatal Care. 2014;14(6):410-423.

7. Cooper LG, Gooding JS, Gallagher J, Sternesky L, Ledsky R, Berns SD. Impact of a family-centered care initiative on NICU care, staff and families. J Perinatol. 2007;27(suppl 2):S32-S37.

8. Bracht M, Ardal F, Bot A, Cheng CM. Initiation and maintenance of a hospital-based parent group for parents of premature infants: key factors for success. Neonatal Netw. 1998;17(3):33-37.

9. Melnyk BM, Feinstein NF, Alpert-Gillis L, et al. Reducing premature infants' length of stay and improving parents' mental health outcomes with the Creating Opportunities for Parent Empowerment (COPE) neonatal intensive care unit program: a randomized, controlled trial. Pediatrics. 2006;118(5):e1414-e1427

10. Schlittenhart JM, Smart D, Miller K, Severtson B. Preparing parents for NICU discharge: an evidence-based teaching tool. Nurs Womens Health. 2011;15(6):484-494.

11. Arnold J, Diaz MC. Simulation training for primary caregivers in the neonatal intensive care unit. Semin Perinatol. 2016:40(7):466-472.

12. Tofil NM, Rutledge C, Zinkan JL, et al. Ventilator caregiver education through the use of high-fidelity pediatric simulators: a pilot study. Clin Pediatr (Phila). 2013;52(11):1038-1043.

13. Morey JA, Gregory K. Nurse-led education mitigates maternal stress and enhances knowledge in the NICU. MCN Am J Matern Child Nurs. 2012;37(3):182-191

14. Kowalski WJ, Leef KH, Mackley A, Spear ML, Paul DA Communicating with parents of premature infants: who is the informant? J Perinatol. 2006;26(1):44-48.

15. Dusing SC, Van Drew CM, Brown SE. Instituting parent education practices in the neonatal intensive care unit: an administrative case report of practice evaluation and statewide action. Phys Ther 2012;92(7):967-975

16. Voos KC, Miller L, Park N, Olsen S. Promoting family-centered care in the NICU through a parent-to-parent manager position. Adv Neonatal Care. 2015:15(2):119-124.

17. Brett J, Staniszewska S, Newburn M, Jones N, Taylor L. A systematic mapping review of effective interventions for communicating with, supporting and providing information to parents of preterm infants. BMJ Open. 2011;1(1):e000023.

18. Mackley A, Winter M, Guillen U, Paul DA, Locke R. Health literacy among parents of newborn infants. Adv Neonatal Care. 2016;16(4):283-288.

19. Lefkowitz DS, Baxt C, Evans JR. Prevalence and correlates of posttraumatic stress and postpartum depression in parents of infants in the neonatal intensive care unit (NICU). J Clin Psychol Med Settings. 2010;17(3):230-237.

20. Schwabe L, Wolf OT. Learning under stress impairs memory formation. Neurobiol Learn Mem. 2010;93(2):183-188.

21. The Beryl Institute. The state of patient experience in American hospitals-2011 benchmarking study. 2011. https://www.theberylinstitute.org/store/ViewProduct.aspx id $=769470$. Accessed October 9, 2018.

22. The Beryl Institute. The state of patient experience in American hospitals 2013: positive trends and opportunities for the future. 2013 https://www. theberylinstitute.org/page/PXBenchmarking2013. Accessed October 9, 2018.

23. The Beryl Institute. State of patient experience 2015: a global perspective on the patient experience movement. 2015. https://www.thebery linstitute.org/page/PXBENCHMARKING2015. Accessed December 13, 2016.

24. The Beryl Institute. The state of patient experience: a return to purpose. 2017. https://www.theberylinstitute.org/page/PXBENCHMARKING2017. Accessed July 28, 2017.

\section{Get your Contact Hours Through ANC!}

ANC offers ANCC contact hours through journal articles. These are high quality $C E$ offerings which meet recertification requirements and individual license renewal needs. You can get ANC CE in these easy steps:

1. Read the ANC CE article (we usually publish at least 1 per issue).

2. Visit www.nursingcenter.com/ce/ANC

3. Login to your personal CE Planner account before taking the tests. You will need to register to get access to a CE Planner. Your planner will keep track of all your CE activities for you.

4. Take the test! If you pass, you can print your certificate of earned contact hours and access the answer key. If you fail, you have the option of taking the test again at no additional cost.

5. Remember, if you are a NANN member, you receive a discount on ANC CE! Contact NANN and get the discount code to use at checkout. 